\title{
Parasitic myoma after supracervical laparoscopic histerectomy
}

\author{
Maurício Paulo Angelo Mieli ${ }^{a}$, Ana Maria Sampaio Moreira Grell ${ }^{\mathrm{b}}$, \\ Ricardo dos Santos Simões ${ }^{a}$, Leandro Accardo de Mattos ${ }^{c}$
}

Mieli MPA, Grell AMSM, Simões RS, Mattos LA. Parasitic myoma after supracervical laparoscopic histerectomy. Autopsy Case Rep [Internet]. 2013;3(2):45-49. http://dx.doi.org/10.4322/acr.2013.017

\section{ABSTRACT}

\begin{abstract}
Parasitic myoma is a condition defined as a myoma of extrauterine nourishing. It may occur spontaneously or as a consequence of surgical iatrogeny, after myomectomy or videolaparoscopic supracervical hysterectomy, due to remaining residues of uterine tissue fragments in the pelvic cavity after morcellation. The authors describe two cases in which the patients were submitted to videolaparoscopic supracervical hysterectomy and uterine body removal through morcellation. The sites of development of the parasitic myomas were next to the cervix stump in Case 1, and next to the right round ligament in Case 2. These parasitic myomas were removed by videolaparoscopy. After myomectomies or videolaparoscopic supracervical hysterectomies followed by uterine fragments removal from the pelvic cavity through morcellation, meticulous searching for residues or fragments of uterine tissue is mandatory to prevent the occurrence of parasitic myomas.
\end{abstract}

Keywords: Laparoscopy; Myoma; Histerectomy; Laparoscopy/adverse effects; Laparoscopy/ methods; Leiomyoma/surgery.

\section{CASE REPORTS}

We present the cases of two patients. Case 1 is a 45-year-old patient, and Case 2 is a 42-yearold patient, who looked medical care, complaining of lower abdominal pain. Both patients had a past medical history of uterine myomatosis treated by videolaparoscopic supracervical hysterectomy. In both cases, the uterine body was removed from the pelvic cavity by morcellation. The diagnostic work up, in these two cases, included the endovaginal ultrasonography with Doppler fluxometry, which resulted in the presence of a well-delimited, poorly vascularized, hypoechoic pelvic mass (Figures 1 and 2). In Case 1, the mass was located next to the cervical stump measuring $5 \mathrm{~cm}$ in its longest axis. In Case 2, a similar image was shown in the adnexal region measuring $6 \mathrm{~cm}$ in its longest axis. For both cases, Ca 125, Ca 19.9, Ca 15.3, CEA, HCG, a-fetoprotein were normal, as expected for the diagnosis of parasitic myoma. Pelvic magnetic resonance imaging (MRI) confirmed the ultrasonography findings (Figures 3 and 4).

These two patients were submitted to videolaparoscopic surgery for diagnosis and treatment. In Case 1, a hard mass with fibromuscular

\footnotetext{
a Department of Gynecology - Hospital Universitário - Universidade de São Paulo, São Paulo/SP - Brazil.

${ }^{b}$ Department of Gynecology - Hospital Israelita Albert Einstein, São Paulo/SP - Brazil.

' Laboratories - DIGIMAGEM e RDO Diagnósticos Médicos - São Paulo/SP - Brazil.
}

Copyright $\odot 2013$ Autopsy and Case Reports - This is an Open Access article distributed of terms of the Creative Commons Attribution NonCommercial License (http://creativecommons.org/licenses/by/3.0/) which permits unrestricted non-commercial use, distribution, and reproduction in any médium provided article is properly cited. 


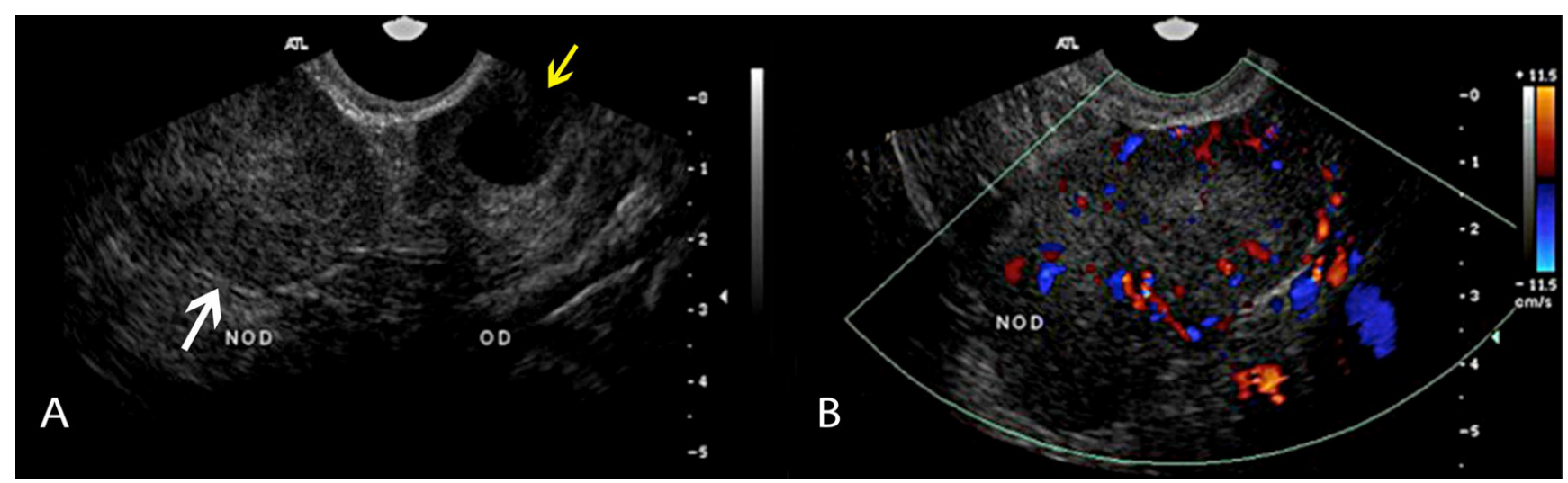

Figure 1 - Case 1 - Transvaginal echography. A - Well-circumscribed fibrous nodule (white arrow) and an adjacent ovary (yellow arrow); B - A colored Doppler shows that the nodule vascularization comes from the adjacent mesentery. No vascular pedicle was depicted coming from the residual cervix or ovary.

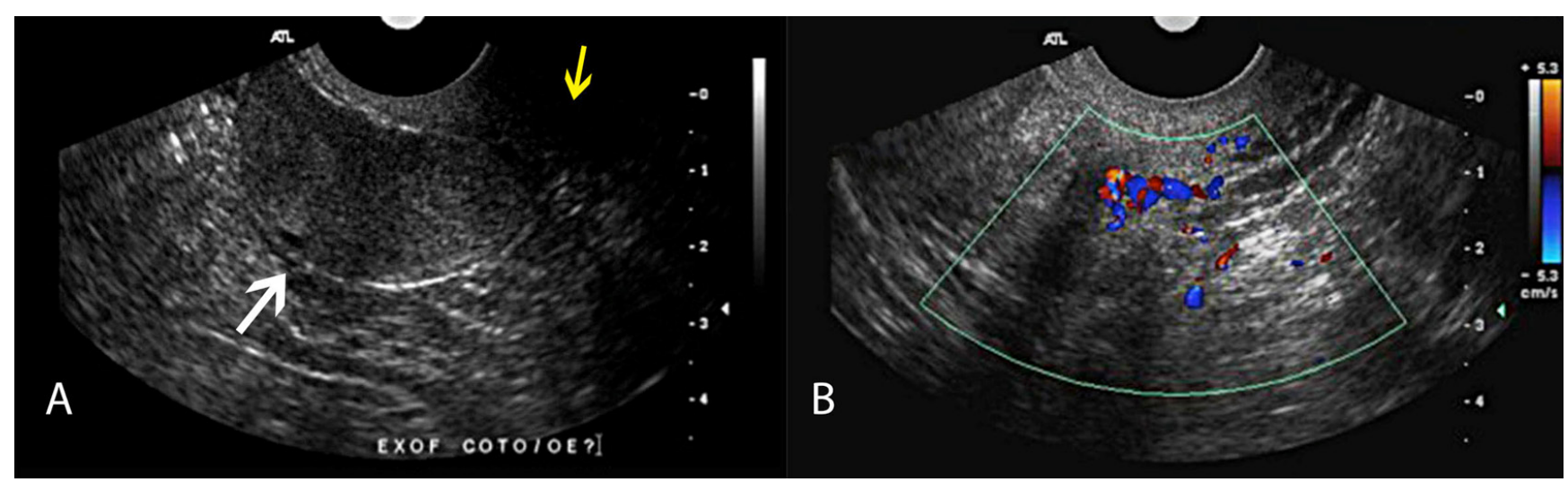

Figure 2 - Case 2 - Transvaginal ultrasonography. A - A well-circumscribed fibrous nodule (white arrow) in contact with the remaining cervix (yellow arrow); B - The colored Doppler show that the nodule is vascularized.

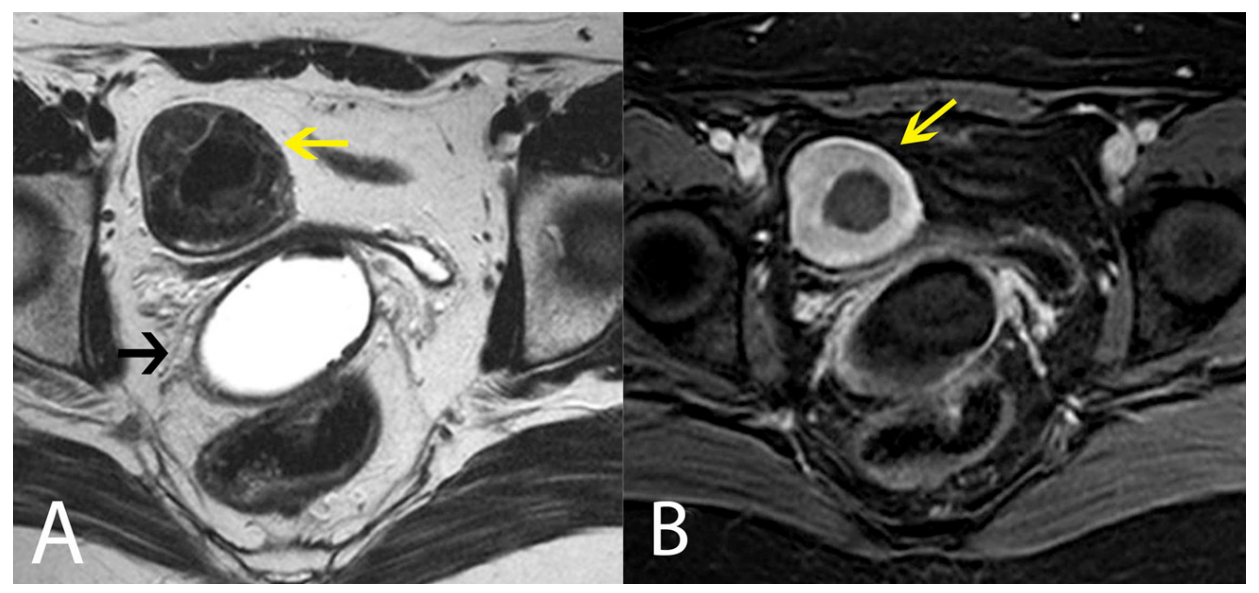

Figure 3 - Case 1 - Magnetic resonance imaging of the pelvis. A - T2-weighted image showing a fibrous nodule in the right adnexal topography (yellow arrow), and the gel filled vagina (black arrow); $\mathbf{B}$ - The T1weighted image after the contrast medium injection showing a vascularized nodule.

appearance next to the uterine stump was found (Figure 5). In Case 2, a hard and fibromuscular mass next to the round right ligament stump was found (Figure 6). The surgical diagnosis was leiomyoma, which were removed with the aid of a morcellator. The pathologic examination resulted in the diagnosis of leiomyoma in both cases.

\section{DISCUSSION}

Uterine leiomyomas affect $20-30 \%$ of women older than 35 years. The incidence may be on the rise since many women are postponing their reproductive careers. ${ }^{1}$ Extrauterine leiomyomas are rare, benign, and may arise in nearly any anatomic 


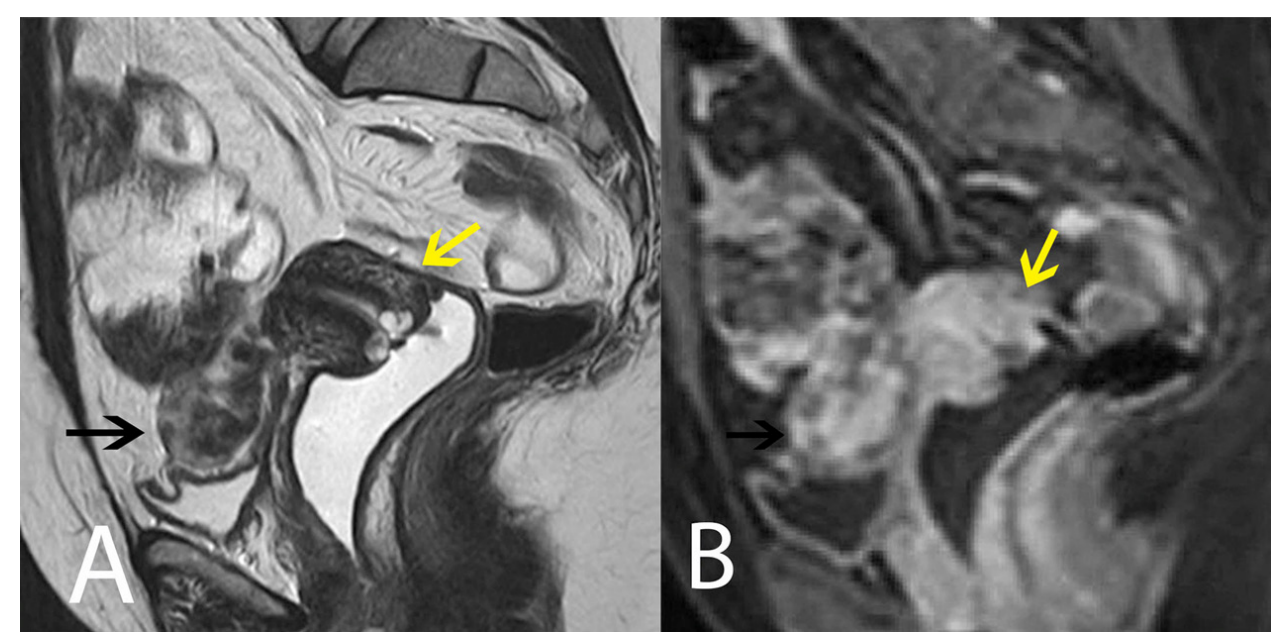

Figure 4 - Case 2 - Magnetic resonance imaging of the pelvis. A - T2-weighted image showing a wellcircumscribed solid mass in the right adnexal topography (black arrow). The fibrous nature of the nodule corresponds to the black component of the nodule. The yellow arrow points to the remaining cervix; B - T1weighted image after the intravenous contrast injection showing the vascularization of both structures.

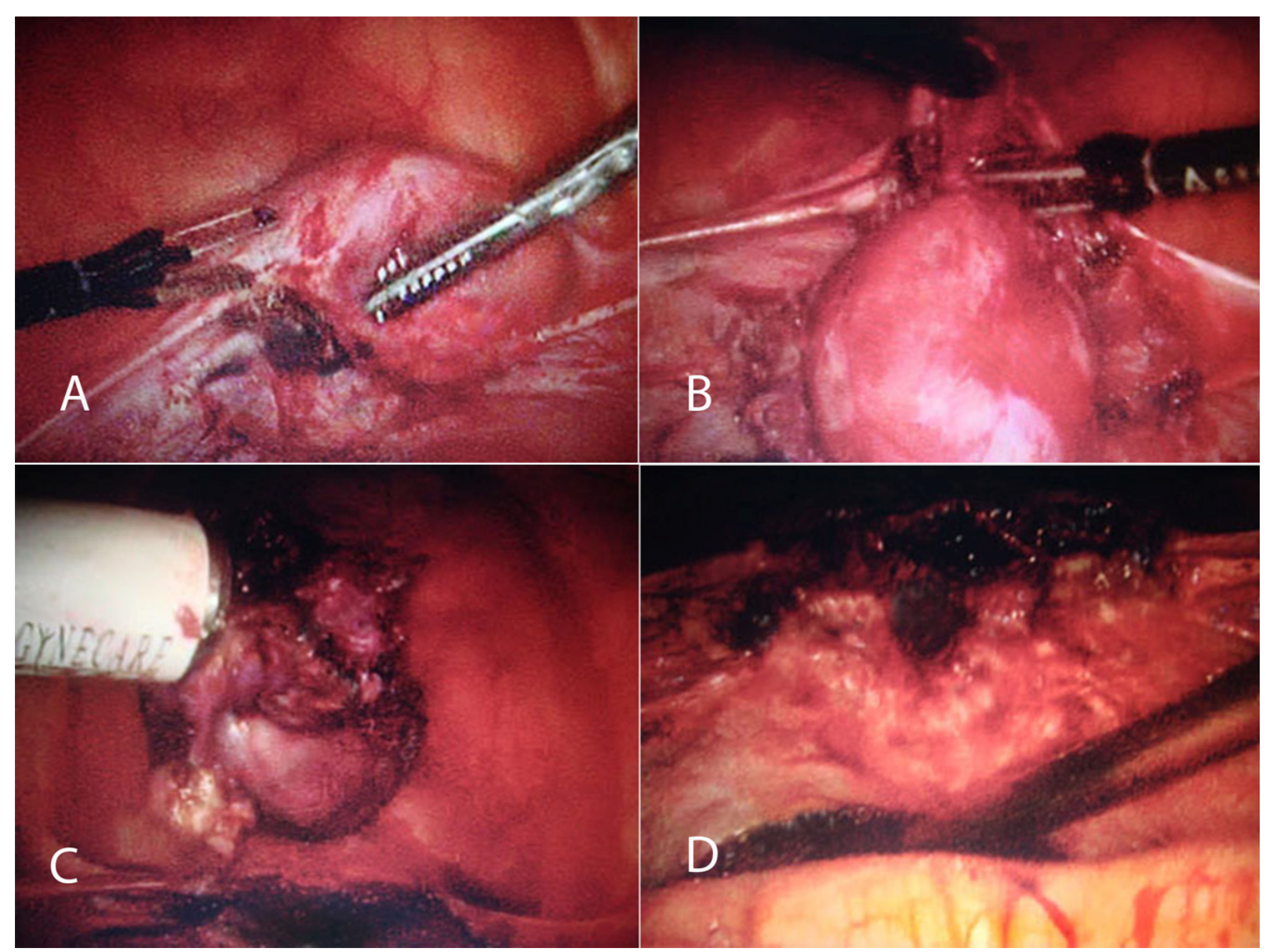

Figure 5 - A - Parasitic leiomyoma of the uterine cervix stump; B - Laparoscopic removal of parasitic leiomyoma of the uterine cervix stump; C - Laparoscopic morcellation of parasitic leiomyoma; D - Inspection of the abdominal cavity after morcellation.

site. Their unusual growth pattern may even mimic malignancy and can result in serious diagnostic errors, frequently representing a clinical dilemma. ${ }^{2}$

This entity was first described in the early 1900 s and remains a rare condition. ${ }^{3}$ The first reports showed that pedunculated subserous uterine leiomyomas adhered to surrounding structures, lost their original uterine blood supply, detached from the uterus, and received an auxiliary blood supply, thereby becoming 'parasitic.' What appeared to be a rarity has been increased more recently, when 


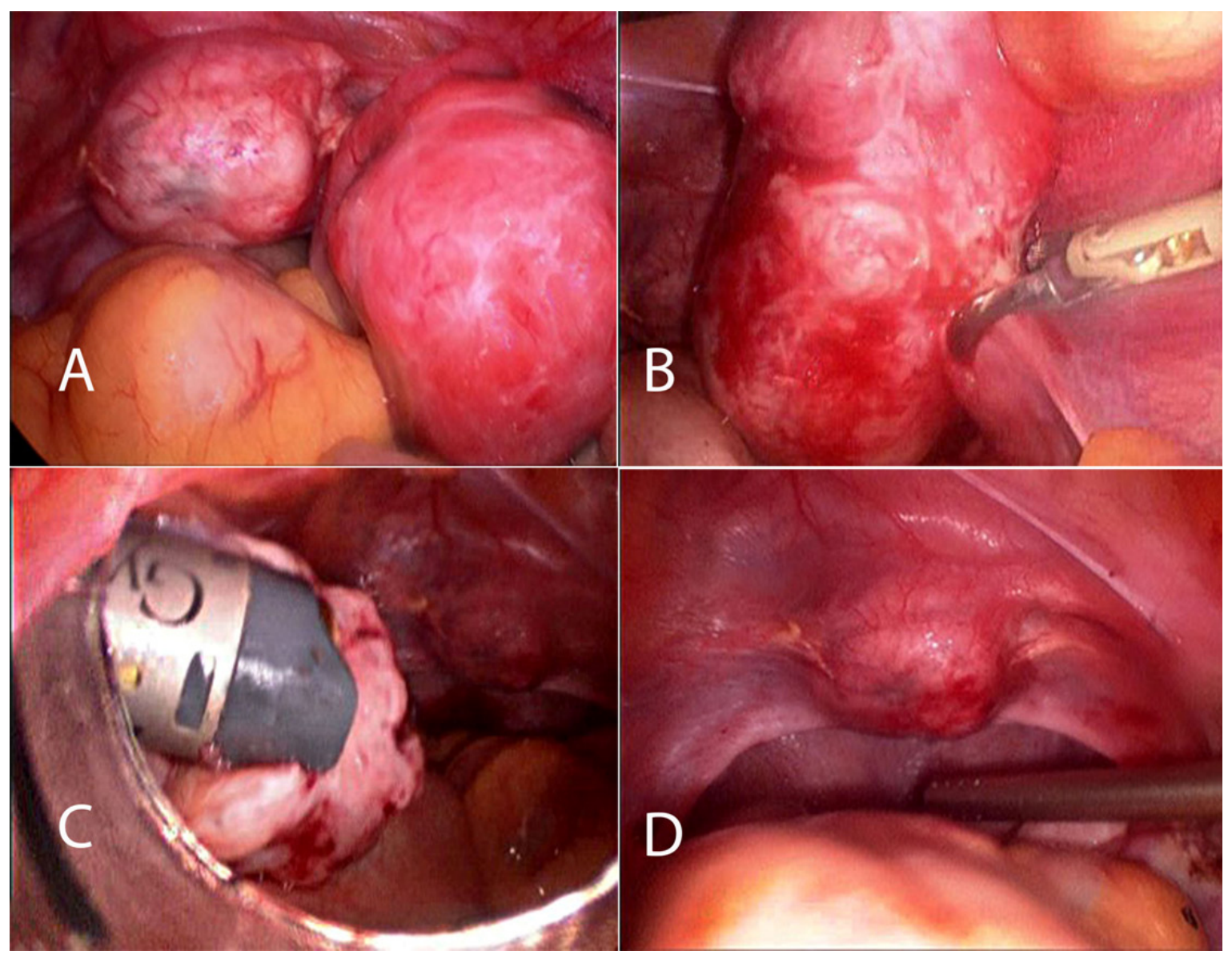

Figure 6 - A - Parasitic leiomyoma of the round ligament stump; B - Laparoscopic removal of parasitic leiomyoma; C - Laparoscopic morcellation of parasitic leiomyoma; D - Inspection of the abdominal cavity after morcellation.

the association with the history of a surgery, or a laparoscopic procedure involving morcellation of the uterus or myomas, was present. ${ }^{3}$

Therefore, myomas may be iatrogenically created after uterine fibroid surgery, particularly if the morcellation technique is used. With the surge of laparoscopic gynecological procedures, especially laparoscopic myomectomy or laparoscopic supracervical hysterectomy, the likelihood for developing parasitic myomas is increasing and thus they are being recognized more frequently., In a series of 423 laparoscopic procedures for hysterectomy or myomectomy, where a morcellator was used, the incidence of parasitic myoma was $0.9 \%{ }^{6}$

Nezhat and $\mathrm{Kho}^{3}$ reported two cases of parasitic myomas; one occurring after administration of a gonadotropin-releasing hormone agonist, and the other after magnetic resonance-focused ultrasound treatment of uterine myomas. They suggested a similar pathogenesis as that of the parasitic myomas traditionally described in the literature; that is, when the uterine blood supply is diminished to the myoma, it may find an adjacent organ from which to obtain blood supply and thereby become parasitic on this non-uterine source. Thus, parasitic myomas seem to fall into three broad categories: spontaneous development of parasitic myomas from pedunculated myomas; myomas associated with previous uterine surgery, in particular, morcellation; and myomas associated with the restriction of blood supply to the uterus. ${ }^{5}$

It is likely that primary parasitic myomas will continue to be rare occurrences; however, iatrogenically caused parasitic myomas may be diagnosed more commonly in the laparoscopic era. ${ }^{7}$

Some reports showed incidental pelvic masses diagnosed during surgery for other indications. Although these symptomless cases do exist, pain is the cardinal complaint. Peritoneal involvement may also be present in the cases when torsion of parasitic myomas occurs. Palpable abdominal mass, urinary retention and menorrhagia may also be the presentation symptom. Parasitic myomas vary in size, ranging from $1 \mathrm{~cm}$ to $30 \mathrm{~cm}$, and most of them are located in the pelvis and 
parasites of the omentum. The mean age of the diagnosis is 38 years. When a previous surgery is involved in the history, the mean time between the surgery and the diagnosis of parasitic myoma is 26 months. $5,6,8,9$

Ultrasonography, computed tomography, and $\mathrm{MRI}$ are the best imaging methods for diagnosing extrauterine leiomyomas. The superb contrast resolution and multiplanar capabilities of MRI make it particularly valuable for characterizing these tumors, which usually show low-signal intensity similar to that of smooth muscle on T2-weighted images. ${ }^{2}$

\section{CONCLUSION}

We emphasize that, despite their rareness, the diagnosis of parasitic myomas should always be included in the differential diagnosis of patients complaining of abdominal pain or have palpable masses and who present a history of a previous operation in which morcellation techniques were used.

With the increasing rates of laparoscopic procedures, a rise in the incidence of parasitic myomas is expected.

Gynecologists and surgeons should be aware of the risk of iatrogenic parasitic myoma formation. All necessary intraoperative precautions must be taken to avoid their occurrences; namely, meticulous surgical techniques with systematic surveying of the entire cavity and complete retrieval of even the smallest fragments of morcellated tissue.

\section{REFERENCES}

1. Van Katwijk C, Peeters LLH. Clinical aspects of pregnancy after the age of 35 years: a review of the literature. Hum Reprod Update. 1998;4(2):185-94. http://dx.doi.org/10.1093/ humupd/4.2.185

2. Fasih N, Prasad Shanbhogue AK, MacDonald DB, et al. Leiomyomas beyond the uterus: unusual locations, rare manifestations. Radiographics. 2008;28(7):1931-48. PMid:19001649. http://dx.doi.org/10.1148/rg.287085095

3. Nezhat C, Kho K. latrogenic myomas: new class of Myomas? J Minim Invasive Gynecol. 2010;17(5):544-50. PMid:20580324. http://dx.doi.org/10.1016/j.jmig.2010.04.004

4. Kho KA, Nezhat C. Parasitic myomas. Obstet Gynecol. 2009;114(3):611-5. PMid:19701042. http://dx.doi. org/10.1097/AOG.0b013e3181b2b09a

5. Hameed N, Ali MA. Recent trends in Laparoscopic myomectomy. J Ayub Med Coll Abbottabad. 2004;16(1):58-63. PMid:15125185.

6. Cucinella G, Granese R, Calagna G, Somigliana E, Perino A. Parasitic myomas after laparoscopic surgery: an emerging complication in the use of morcellator? Description of four cases. Fertil Steril. 2011;96(2):e90-6. PMid:21719004. http:// dx.doi.org/10.1016/j.fertnstert.2011.05.095

7. Dan D, Harnanan D, Hariharan S, Maharai R, Hosein I, Naraynsingh. Extrauterine leiomyomata presenting with sepsis requiring hemicolectomy. Rev Bras Ginecol Obstet. 2012; 34(6):285-9. PMid:22801604.

8. Sinha R, Sundaram M, Lakhotia S, Kadam P, Rao G, Mahajan C. Parasitic myoma after morcellation - case report. J Gynecol Endosc Surg. 2009 Jul;1(2):113-5. PMid:22442523 PMCid:3304268. http://dx.doi.org/10.4103/0974-1216.71612

9. Larraín D, Rabischong B, Khoo CK, Botchorishvili R, Canis $M$, Mage $G$. latrogenic parasitic myomas: unusual late complication of laparoscopic morcellation procedures. J Minim Invasive Gynecol. 2010;17(6):719-24. PMid:20655285. http://dx.doi.org/10.1016/j.jmig.2010.05.013

\section{Conflict of interest: None}

Submitted on: $18^{\text {th }}$ January 2013

Accept on: $21^{\text {th }}$ May 2013

Correspondence: Department of Gynecology Hospital Universitário da Universidade de São Paulo

Av. Prof. Lineu Prestes, 2565 - Cidade Universitária - São Paulo/SP - Brazil

CEP: 05508-000 - Phone: +55 (11) 3091-9317

E-mail: mpamieli@gmail.com 